\title{
Letter Sound Awareness among Grade One and Two Pupils with Hard of Hearing Impairment in Selected Schools in Lusaka District, Zambia
}

\author{
Rose Chikopela \\ University of Zambia, School of Education \\ P.O. Box 32379, Lusaka. Zambia \\ Daniel Ndhlovu \\ University of Zambia \\ Institute of Distance Education \\ P.O. Box 32379, Lusaka. Zambia
}

\begin{abstract}
This is an extract from a PhD thesis based on one of the objectives which sought to investigate the predictive role of oral language in phonemic/phonics development in pupils with hearing impairment in grades one and two in Lusaka Zambia. Since the study opted to assess all the children in their respective grades ex post facto research design was used. Five schools took part in the study. The sample comprised 60 pupils of which 31 were girls and 29 were boys. Pupils were tested individually at the end of grade one and two using the Basic Skills Assessment Tool (BASAT), Peabody Picture Vocabulary Test (PPVT) and One-Word Picture Vocabulary Test (OPVT). Bivariate correlations were computed to analyse data. Results revealed that pupils with hard of hearing displayed insufficient knowledge in letter sound knowledge and sound blending tasks. It was established that both expressive and receptive vocabularies did not predict sound awareness in pupils with hard of hearing due to inadequate instruction in this area. Based on the findings, the study recommended that teachers of pupils with hard of hearing should utilize oral language when teaching pupils phonemic/phonics skills. Pupils with hearing impairment should also be identified early, possibly at entry into preschool or grade one so that they are provided with hearing aid device to help them speed up the acquisition of oral language skills.
\end{abstract}

Keywords: Oral language, phonemic/phonics awareness, hard of hearing.

\section{INTRODUCTION}

\subsection{Background}

Oral language development is considered one of the indicators of phonemic development in pupils with hard of hearing (Rachel \& Friedman 2006). Almost all classroom-based learning relies on oral language thereby making it also the foundation for hard of hearing pupils' learning. Phoneme development is a long and slow process for children with hard of hearing. Awareness of phonemes is present at birth and phoneme analysis becomes operational by about 6 months of age, when infants begin to extract words from the speech stream (spoken phrases) and build a receptive vocabulary (Vihman, 1993). Pupils with a good understanding of phonemic and phonological awareness have the underlying framework in place for reading (decoding) and writing (encoding) when letter-sound correspondences (phonics) are learned (Adams, Foorman, Lundberg, and Beeler, 1998). Because of the predictive power of oral language in determining phonemic and phonological development and literacy in hearing students, the role of oral language in phonemes and phonology development in pupils with hard of hearing vis-`a-vis reading has been a subject of great interest in this study. The question for this study was to what extent do pupils with hard of hearing in grade one and two know about sounds of letters? To understand how oral language contributes to phonemic development in hard of hearing pupils, the current study applied the Phonological Sensitivity Approach (PSA) by Dickinson et al. (2003).

Proponents of this model reveal that oral language is directly related to phonemic awareness and it is this phonemic awareness that enhance development of phonological skills and consequently reading (Poe, Burchinal, \& Roberts, 2004). This approach envisages that vocabulary and discourse skills are 
key in the emergence of phonological sensitivity (i.e., ability to detect and manipulate the sound structure of oral language), phonological memory (i.e., short term memory for sound based information, and phonological naming (i.e., retrieval of phonological information from long-term memory), and it is these skills that uniquely predict reading skills once children enter school (Matafwali, 2010).

\section{Methodology}

This study used ex post facto research design to investigate cause-and-effect relationships between independent (oral language) and dependent (hard of hearing pupils) variables. This design is used in situations that do not permit the randomization and manipulation of variables of experimental research (Ary et al., 2010).

\subsection{Population}

The target population of this study comprised all pupils with hard of hearing who were in grades one and two in term three in the selected schools. This population was chosen because it had the characteristics of the target population.

\subsection{Sample and Sampling Technique}

The sample for this study consisted of 60 pupils with hard of hearing. All the pupils in grade one and two in term three, 2016 made the sample in the selected schools. Schools that were part of this study were selected using simple random sampling.

\subsection{Instruments and Procedure for Data Collection}

The Basic Skills Assessment Tool (BASAT) was used to assess pupil's sound awareness skills. Two tests were used to tap expressive and receptive language in pupils with hard of hearing. The Peabody Picture Vocabulary Test (PPVT) was used to assess receptive vocabulary and the Fink et al (2012) version was used because it was adapted to the Zambian context. It was used to measure the knowledge of a child in common items found in the environment. One-Word Picture Vocabulary Test (OPVT) was used to assess expressive vocabulary. The assessment tool was developed by the researcher to test receptive language of pupils in common items found in the environment.

\subsection{Data Analysis}

Data was analysed quantitatively using SPSS version 21. Information obtained from the BASAT, Peabody and One-word picture vocabulary test was analysed using bivariate correlations to investigate how the variables in the study were associated and if oral language had an influence on this performance.

\section{RESUlTS AND DISCUSSION}

To understand how the variables in the study are associated and if oral language had an influence on this performance, bivariate correlations were computed on all variables in the analyses. The association of the variables with one another was weak to moderate as illustrated in table 1 .

Table1. Bivariate correlations $(n=60)$

\begin{tabular}{|c|c|c|c|c|c|c|c|c|c|c|}
\hline & Letters & Sounds & Initial & Ending & Blending & Memory & Receptive & Expressive & Age & Gender \\
\hline Letters & -- & & & & & & & & & \\
\hline $\begin{array}{l}\text { Letter } \\
\text { Sounds }\end{array}$ & $.292 *$ & -- & & & & & & & & \\
\hline Initial sound & -.031 & .089 & -- & & & & & & & \\
\hline $\begin{array}{l}\text { Ending } \\
\text { sound }\end{array}$ & -.086 & .111 & $.737 * *$ & -- & & & & & & \\
\hline Blending & .029 & -.024 & .223 & $.275^{*}$ & -- & & & & & \\
\hline Memory & $.526 * *$ & $.488 * *$ & .074 & .144 & .068 & -- & & & & \\
\hline $\begin{array}{l}\text { Receptive } \\
\text { language }\end{array}$ & $.358 * *$ & .092 & .126 & .149 & .094 & $.282 *$ & -- & & & \\
\hline $\begin{array}{l}\text { Expressive } \\
\text { Language }\end{array}$ & $.255^{*}$ & .138 & -.027 & .150 & -.092 & .204 & $.341 * *$ & -- & & \\
\hline Age & .111 & -.058 & -.077 & -.078 & \begin{tabular}{|l|}
-.055 \\
\end{tabular} & -.160 & .137 & .228 & -- & \\
\hline Gender & -.063 & -.087 & -.206 & -.102 & -.146 & -.138 & .160 & .093 & .145 & -- \\
\hline Grade & .012 & .104 & .197 & .235 & .127 & .077 & .132 & .118 & .081 & -.033 \\
\hline
\end{tabular}


Expressive and receptive language proficiency, letter knowledge, letter sound knowledge and blending had weak to moderate correlation. The correlation between expressive language and letter knowledge was moderate $\left(\mathrm{r}=.25^{*}\right)$. Between letter knowledge and letter sounds the correlation was $(\mathrm{r}=.29 *)$, whereas letter sound and sound blending it was rather low $(\mathrm{r}=.029)$. These correlations were in line with studies which indicates that oral language abilities stimulate phonological skills (Matafwali, 2010; Mwanza, 2015) albeit weak in this study. Age, gender and grade also had weak correlations with letter sound knowledge and expressive language. This is due to the fact that hard of hearing pupils are not taught sound awareness as well as sound blending skills because these tasks demand the use of oral language hence teachers rely more on sign language. In addition, there was a high correlation between working memory and letter knowledge $(\mathrm{r}=.52 * *)$ implying that pupils have mastered the letters of the alphabet because the task does not demand use of oral language.

\subsection{Oral Language as a Predictor of Letter Sound Knowledge and Sound Blending}

The relationship between oral language and letter sound knowledge was examined by testing letter naming and letter sound knowledge and correlating it with receptive and expressive language. It was anticipated that alphabetic skills and language skills would be relatively closely related to each other and that sound blending skills would be related to both. Such a pattern of results would be taken as support for the Phonological Sensitivity Approach (PSA), which suggests that general oral-language abilities, especially vocabulary, provide the critical basis for the emergence of phonological sensitivity, which thereafter is the key language skill. This supports the view by Lonigan (2006) and Dickinson et al, (2003) who indicate that general language abilities and vocabulary, rather than receptive and expressive vocabulary alone have a causal relationship with the development of phonological awareness in pupils.

The correlation analysis between oral language abilities and letter sound awareness tasks revealed that expressive and receptive language proficiency, letter knowledge, letter sound knowledge and blending were all weak to moderate. Although the correlations were not high, there was evidence showing existence of this pattern of correlation in pupils with hard of hearing thus supporting the Phonological Sensitivity Approach (Dickinson et al., 2003) that emphasised the importance of oral language in acquisition of these skills.

Results revealed a moderate correlation between expressive language and letter knowledge and between letter knowledge and letter sounds. These correlations were in line with previous work that suggested that oral language abilities stimulate phonological skills and act as subsequent contributors to literacy development (Matafwali, 2010; Chikopela, 2013; and Mwanza, 2015). The findings on letter knowledge support earlier findings by Matafwali \& Bus (2013) that proficiency in oral language has a longitudinal effect on letter knowledge and phonological awareness. One possible explanation for this type of performance on letter knowledge could probably be due to intensive practice in grade one through to grade two regardless of the language used by teachers to deliver lessons in this area. Conversely, the weak relationship between oral language and sound awareness tasks portray luck of instruction in this area. Most teachers seem not to know that pupils with hard of hearing equally can learn sounds just like hearing pupils in that, they also have functional hearing and that it is these sounds that would enable them learn to read.

The results on research done by Burgess et al (1998) and Wagner et al (1994) on letter knowledge were in congruent with this study and other studies of young children (Gillon, 2004; Rvachew, Ohberg, Grawberg \& Heyding, 2003; Stahl \& Murray, 1994) that have found a predictive relation between phonological sensitivity and later letter knowledge and between letter knowledge and both current and subsequent phonological sensitivity.

The findings of this study revealed a high correlation between working memory and letter knowledge implying that pupils had mastered the letters of the alphabet. This could be because the task of mastering letters does not demand use of oral language. This could also mean that even when pupils are taught using sign language, oral language has no bearing on performance on this task. As a result both grades one and two pupils with hard of hearing continued to express this knowledge and had no challenges in this area. In contrast, Chikopela (2013) found that it was much easier for deaf and hard of hearing pupils to name the letters shown to them than reciting the letters from memory. 
It is noteworthy that a good performance was portrayed on letter naming task. This could be due to the fact that these pupils learn through picture and word association hence easy to remember the letters shown to them. This finding is similar to that of Annalene and Natale (2010) who suggest that welldeveloped sign language skills and visual coding strategies that are based on sign language may offer deaf pupils phonological or orthographic link, thus enhancing their written English skills which further help them with their reading skills at school.

The findings could also imply that the first instruction in reading in grade one requires pupils to know all the 26 letters of the alphabet, a trend which also continues in grade two. In this regard, most hard of hearing pupils seem to be doing fine in this area regardless of instruction in oral language because it is easy for teachers to demonstrate the letter symbols to the pupils using sign language and make them sign repeatedly until this skill is learnt. In addition pupils are shown the letters as part of the demonstration. Similarly, Haptonstall-Nyakaza and Schick (2007) in their study show that deaf pupils acquire finger spelled words as lexical items without formal instruction very early in life thus find it easy for them to learn letters in grade one. Corollary, Chikopela (2013) revealed that it was also easy for most pupils with hearing impairment to recite and name the letters of the alphabet. This clearly shows that at grade one level the first instruction given to pupils in reading is that of knowing the letters of the alphabet hence it is much easier to remember and that at this level they have also not learnt a lot of things that they are required to remember. Both grades one and two pupils with hard of hearing were able to name the letters that were shown using both oral and sign language.

It was rather strange that there was a very low correlation between letter sound knowledge and sound blending. A plausible explanation to this type of performance could be that pupils with hard of hearing were not taught using oral language and that, this could have been even hard for teachers to introduce sound awareness tasks prior to alphabetic lessons that are taught using sign language. The teachers in the study also confirmed that they mostly made use of sign language when delivering literacy lessons to these pupils. These findings therefore seem to suggest that when pupils with hard of hearing lack proficiency in oral language instruction, they may experience significant difficulties developing sound awareness as well as sound blending skills which will eventually have a negative impact on their ability to acquire reading skills which are essential in academic advancement.

These findings are inconsistent with Krystal \& Melanie (2014) who provides evidence that initial sound segmentation training increased children's performance on the initial sound segmentation assessment measures in the children with hearing loss. In their study, phonological awareness training was associated with an increase in phonological awareness skills for the children with hearing loss. In contrast to the present study, there is no evidence of phonological awareness training in pupils with hard of hearing in most schools. These outcomes confirm the hypothesis of Dickinson et al., (2003) that a deficit in oral language might alter the pattern of association between language and alphabetic knowledge and between these skills and phonological skills.

Another finding in contrast with this study is Sue's (2000) that proved beyond reasonable doubt that phonics intervention in hard of hearing pupils help to improve phoneme manipulation, letter-sound knowledge, segmenting, blending, reading and spelling. The results further showed strong, positive effects of the phonographix intervention on the development of grapheme-phoneme correspondence knowledge, and the acquisition of blending, segmenting and phoneme manipulation skills all of which lead to the development of word decoding and spelling skills. These results provides support for the view that structured and focused teaching of phoneme segmenting, blending and manipulation skills and of grapheme-phoneme correspondence does accelerate development of these skills and acquisition of this knowledge in hearing impaired children which is not the case in this study, even when pupils have functional hearing.

Research on effective teaching strategies for deaf and hard of hearing pupils is even more limited within the Zambian context than internationally. Most teachers who teach pupils with hearing impairment in Zambia are not trained in special education and do not make use of oral language when teaching making it difficult for pupils to understand the lesson (Chikopela, 2013).

\section{CONCLUSION AND RECOMMENDATIONS}

Based on the study findings it is concluded that pupils with hard of hearing lacked proficiency in oral language instruction as a result were experiencing significant difficulties developing letter sound awareness and sound blending skills which are essential in literacy skills. The correlation analysis 
revealed that expressive and receptive language proficiency, letter knowledge, letter sound knowledge and blending were all weakly to moderately related with one another. It was established that the weak relationship between oral language and sound awareness tasks was as a result of luck of instruction in this area. Most teachers seem not to know that pupils with hard of hearing can equally learn sounds just like hearing pupils in that, they also have functional hearing and that it is these sounds that would enable them to learn to read.

The study therefore recommends that:

- Teachers of the hard of hearing pupils should utilize oral language when teaching phonemic/phonics skills to pupils with hard of hearing.

- Pupils with hearing impairment are identified early by the teachers, possibly at entry into preschool or grade one so that they are provided with hearing aid device to help them speed up the acquisition of oral language skills.

- The training institutions should train teachers for the hard of hearing in sound awareness to ensure quality delivery of lessons in this area.

- The researchers also recommends that schools should conduct Continuous Profession Development (CPD) programmes for teachers to learn how to teach phonemic and phonological skills to the hard of hearing impairment pupils.

\section{REFERENCES}

Adams, M. J., B. R. Foorman, I. Lundberg, and T. Beeler. (1998). Phonemic Awareness in Young Children:A Classroom Curriculum. Paul Brookes Publishing Co.,

Annalene van Staden \& Natale A. le Roux (2010). The Efficacy of Fingerspell Coding and Visual Imaging Techniques in Improving the Spelling Proficiency of Deaf Signing Elementary-Phase Children: A South African Case Study Published online: Springer Science+Business Media, LLC 2010

Ary, D., Jacobs L.C., Sorensen C.K, (2010). Introduction to research in education. Eighth Edition. Belmont, CA: Wadsworth Publishing Company.

Burgess, S., Hecht, S. \& Lonigan, C. (2002). The Relations of Home Literacy Environment (HLE) to the Development of Reading Related Abilities. A One Year Longitudinal Study. Reading Research quarterly $37,408-426$.

Chikopela, R. (2013). The Impact of New Breakthrough to Literacy programme on reading performance of learners with hearing impairment. Unpublished Master Thesis. Lusaka: University of Zambia.

Dickinson, D.K., McCabe, A., Anastosopolous, L., Peisner-Feinberg, E.S. \& Poe, M.D. (2003). The Comprehensive Approach to Early Literacy: The Interrelationship among Vocabulary, Phonological Sensitivity, and Print Knowledge among Preschool aged Children. Journal of Educational Psychology 95, 465-481.

Fink, G., Matafwali, B., Corrina, M. and Stephanie, S. Z. (2012). The Zambian Early Childhood Development Project 2010 Assessment Final Report.

Gillon, G. T. (2004). Phonological awareness: From research to practice. New York: Guilford Press.

Haptonstall-Nyakaza, T. S., and Schick, B. (2007). The transition of fingerspelling to English print: facilitating English decoding. Journal of Deaf Studies and Deaf Education, 12(2), 172-183.

Krystal, L. W. \& Melanie, C. S. (2010). Phonemic Awareness Training with Children with Hearing Loss. Vanderbilt University School of Medicine.

Lonigan, C.J. (2006). Conceptualising phonological Processing Skills in Prereaders. In D. K. Dickinson \& S. B. Neuman (Eds.), Handbook of Early Literacy Research (Vol. 2, pp. 77-89). New York: Guilford.

Matafwali, B. (2010). The role of Oral Language in the acquisition of Early Literacy Skills: A case of Zambian Languages and English. Unpublished PhD Thesis. Lusaka: University of Zambia.

Matafwali, B.\& Bus, A.G. (2013). Lack of Familiarity with the Language of Instruction: A Main Cause of Reading Failure by Grades One and Two Pupils in Zambia. Insights on Learning Disabilities 10(2) 31-44. 
Mwanza-Kabaghe, S. (2015). Preschool, executive functions and oral language as predictors of literacy and numeracy skills in first grade.PhD thesis, University of Zambia. Lusaka.

Poe, M. D., Burchinal, M. R. \& Roberts, J. E. (2004). Early Language and the development of children's reading skills. Journal of School Psychology, 42, 315-332.

Rachel, A. \& Friedman, N. (2006). Teaching Phonological Awareness with Deaf and

Hard-of-Hearing Students. Teaching Exceptional Children, Vol. 38, No. 4, pp. 53-58.

Rvachew, S. Ohberg, A. Grawburg, M \& Heyding, J. (2003). Phonological awareness and phonemic perception in 4-year-old children with delayed expressive phonology skills. Am J Speech Lang Pathol, 12(4):463-71.

Stahl, S. A. \& Murray, B. A. (1994). Defining phonological awareness and its relationship to early reading. Journal of Educational Psychology. 86:221-234.

Sue, P. (2000). Assessing the benefits of phonics intervention on hearing impaired children's word reading. Deafness \& Education International, 2(3), pp 165-178

Vihman, M. M. (1993). Variable paths to early word production. Journal of phonetics, 21,61-82.

Wagner, R.K., Torgesen, J.K. \& Rashotte, C.A. (1994). Development of Reading-related Phonological Processing Abilities: New Evidence of Bi-directional Causality from a Latent Variable Longitudinal Study. Developmental Psychology, 30, 73-87.

\section{AUTHORS' BIOGRAPHY}

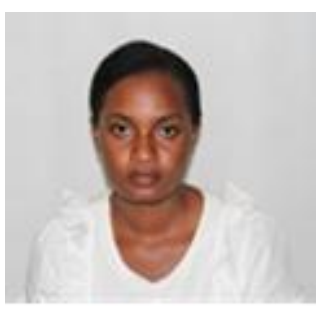

Rose Chikopela is a part-time lecturer in the Department of Educational Psychology, Sociology and Special Education at the University of Zambia. She is currently a $\mathrm{PhD}$ candidate in the same department. Her $\mathrm{PhD}$ thesis is about the role of oral language in phonemic and phonological development in hard of hearing impairment pupils in selected primary schools in Lusaka, Zambia. She has published one article on teaching materials in phonology for pupils with hard of hearing in selected schools of Chongwe District, Lusaka province, Zambia in the International Journal of Multidisciplinary Research and Development (Online ISSN: 2349-4182). Rose has also participated in various national and international education conferences.

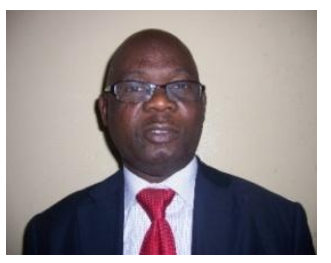

Dr. Daniel Ndhlovu is a Senior lecturer in the Department of Educational Psychology, Sociology and Special Education at the University of Zambia. He holds a doctoral degree in Special Education, Masters degree in Education and Bachelor's degree in Special Education from the University of Zambia. In addition to lecturing, he has held senior administrative positions at the University of Zambia which includes Assistant Dean Postgraduate in the School of Education and Assistant Director Postgraduate in the Institute of Distance Education. Daniel has 29 years teaching and lecturing experience at secondary school, tertiary and university levels of education. He has done numerous research activities and publications in local and international refereed journals. His latest publication is Drug and Alcohol Abuse Prevention Education in Selected Secondary Schools in Zambia: Current Practices authored by Isaac Masiye and Daniel Ndhlovu. International Journal of Humanities Social Sciences and Education (IJHSSE) Online ISSN 2349-0373. 